\title{
Fullerenes: Synthesis and Applications
}

\author{
Ayawei Nimibofa ${ }^{1}$, Ebelegi Augustus Newton, ${ }^{1}$ Abasi Yameso Cyprain ${ }^{1} \&$ Wankasi Donbebe ${ }^{1}$ \\ ${ }^{1}$ Department of Chemical Sciences, Niger Delta Universities, Wilberforce Island, Yenagoa, Bayelsa State, Nigeria \\ Correspondence: Ayawei Nimibofa, Department of Chemical Sciences, Niger Delta Universities, Wilberforce \\ Island, Yenagoa, Bayelsa State, Nigeria. E-mail: ayawei4acad@gmail.com
}

Received: March 19, 2017

Accepted: April 4, 2017

Online Published: June 30, 2018

doi:10.5539/jmsr.v7n3p22

URL: https://doi.org/10.5539/jmsr.v7n3p22

\begin{abstract}
Fullerenes were initially found to be inert, but their unique cage structure and solubility in organic solvents opened up their susceptibility to functionalization via addition and redox reactions. Endohedral and exohedral derivatives of Buckminster fullerene $\left[\mathrm{C}_{60}\right]$ have created a niche in the application of carbon nanomaterials in the medical, electronics, energy and water treatment/conservation sectors.
\end{abstract}

Keywords: Fullerene, Buchminster, Symmetry, Endohedral, Exohedral, Functionalization

\section{Introduction}

Born out of the quest to replicate poly acetylenes discovered in inter-stellar space, fullerene were first produce by Kroto, Curl and Smalley via laser induced evaporation of graphite (Carey, 2003), thus the discovery of Buckminsterfullerene, $\mathrm{C}_{60}$, originated from a research study connecting synthetic chemistry, microwave spectroscopy and radio-astronomy (Kroto, 1982). Fullerene molecules are constituted entirely of carbon with 20 hexagonal and 12 pentagonal rings as their basis of an icosahedral symmetry in a closed cage, each carbon atom in a fullerene molecule is linked to three others (Krätschmer, Lamb, Fostiropoulos, \& Huffman, 1990; Kroto, Heath, O'Brien, Curl, \& Smalley, 1993).

Fullerenes are made up of isomers with homologues ranging from the most studied lower homologues such as $\mathrm{C}_{60}$ and $\mathrm{C}_{70}$ to higher fullerenes like $\mathrm{C}_{240}, \mathrm{C}_{540}$ and $\mathrm{C}_{720}$. Thus they have found usefulness in various fields of science such as separation and determination of chemical species (Dresselhaus, Dresselhaus, \& Eklund, 1996; Baena, Gallego, \& Valcarcel, 2002; Guillaume, Peyrin, \& Grosset, 2000; Ohta et al., 2000; Fang, Zeng, Fan, \& Chen, 2000; Jinno, Tanabe, Saito, \& Nagashima, 1997).

The spontaneous production of fullerene molecule in a chaotic carbon plasma follows a simple nucleation pathway which suggests that when carbon nucleates, curved and closed graphitic shells that are wrapped up under epitaxial conditions are formed (Zhang et al., 1986; Iijima, 1980).

Some researchers have produced and characterized fullerenes obtained from carbon deposits obtained from arc processed graphite and their results show that fullerenes constitute about $10-30 \%$ material produced by carbon arc processes (Krätschmer, Lamb, Fostiropoulos, \& Huffman, 1990; Gerhardt, Löffler, \& Homann, 1987; Howard et al., 1991).

As scientific investigations delve more into understanding the composition of carbon vapour, fluid carbon phases, soot formation processes mechanizing of carbon nucleation and new metal/carbon complexes/intercalation compounds, new advances were made with respect to viable sources, physical and chemical characteristics and applications of fullerenes.

\section{History of the Development of Fullerenes}

This third allotrope of carbon had a very shadowy existence as far back as 1966 when David Jones discussed the possibility of creating graphite ballons (Kroto, 1993; Jones, 1966). Some progress was made in 1970 when Eiji Osawa revealed the prospect of producing $\mathrm{C}_{60}$ molecule made up of 60 carbon atoms in the structure of condensed icosahedron (Osawa, 1970), then in 1971 Eiji Osawa and Zensho Yoshida enumerated the possible aromatic properties of the $\mathrm{C}_{60}$ molecule in a book titled "Aromatic Molecules" (Sheka, Razbirin, \& Nelson, 2011). Subsequently, in 1973 Bochva and Galpern with Stonkevich and coworkers carried out a Huckel calculation of $\mathrm{C}_{60}$ in order to determine its electronic structure (Bochvar \& Galpern, 1973; Stankevich, Nikerov, \& Bochvar, 1984) and in 1980 with the use of general group theoretical techniques Davidson revealed that the distance between 
the highest occupied molecular orbital (HOMO) and the lowest unoccupied molecular orbital (LUMO) could be used to characterize the closed hollow cell of fullerene $\mathrm{C}_{60}$ molecule, and this convincingly indicated chemical stability of the species (Davidson, 1981).

Thus, advances in experimental technique in the chemical physics of clustered molecules and planetary processes linked to inter/circum-stellar molecules lead to the discovery of $\mathrm{C}_{60}$ Buckminster fullerene in 1985 and this paved the way for its extraction and characterization in 1990 (Kroto, 1988).

While studying cyanoacetylenes which were hypothesized to exist in the molecular clouds that surround stars with carbon-rich atmospheres, Harry Kroto combined molecular spectroscopy with measurements made by radio astronomers who were working to detect the same molecules in the material surrounding carbon stars in particular the object known as IRC+10216 (Kroto, 1988).

The existence of relatively large quantities of cyanoacetylenes disputed the then existing model of interstellar chemistry which had earlier forecasted that these molecules were present in much smaller quantities (Heath, 2016). In 1985 Kroto in collaboration with Robert Curl and Rick Smalley at Rice University, Houston, Texas, U. S. A. performed experiments with assistance from graduate students Heath, R. J. Sean O'Brien and Yuan Liu to confirmed that long cyanopolyyenes including those previous detected in space are formed when laser beams were focused on a graphite target, indeed this happenstance proved that $\mathrm{C}_{60}$ molecule was remarkably stable (Krato \& Heath, 1985; Kroto, 1997). Therefore, the discovery of $\mathrm{C}_{60}$ had to wait till the right experiment was done with the appropriate instrument at the right time with the right team on board.

Experimental support for the proposed truncated Icosahedron structure of $\mathrm{C}_{60}$ was derived from a combination of mass-spectra data and circumstantial evidence, this proposed structure which suggested a cage of interlocking pentagon and hexagons was initially greeted with understandable doubt (Kroto, Allaf, \& Balm, 1991; Kroto, 1987). But the skepticism that greeted the truncated icosahedron $\mathrm{C}_{60}$ structure was cleared by the breakthrough made by W. Kratshchemer and D. R. Hutfirm in 1990 with the production of Isolable quantities of $\mathrm{C}_{60}$ from an arc between two graphite rods that burned in a helium atmosphere, with the carbon condensate formed and extracted with the use of an organic solvent (Krätschmer, Lamb, Fostiropoulos, \& Huffman, 1990; Kroto, 1992; Ajie et al., 1990; Howard, McKinnon, Makarovsky, Lafleur, \& Johnson, 1991).

The isolated material was further separated into two components $\mathrm{C}_{60}$ and $\mathrm{C}_{70}$ with chromatographic technique while ${ }^{13} \mathrm{CNMR}$ analysis of $\mathrm{C}_{60}$ component showed a single line resonance which is an indication that all the carbon atoms in this component are equivalent while that for $\mathrm{C}_{70}$ showed five (5) lines and this reveals the existence of other member of the fullerene family (homologues) (Anderson, West, \& Foote, 1997).

Later on, Smalley adopted a technical model to describe the structure of $\mathrm{C}_{60}$, this model had been previously used by reknown American Architect 'Buckminster Fuller' who was a known designer of spherical structures (geodesic dome). Hence the name Buckminster fullerene and exhibit spherical shape with 12 pentagon and 20 hexagon like $\mathrm{C}_{60}$, similar to a soccer ball (Kroto, Heath, O'Brien, Curl, \& Smalley, 1993).

The quest to study the physical and chemical properties of $\mathrm{C}_{60}$ and its higher homologues and new substances produced from these compound opened up a new vista in the expansion of chemistry into diverse areas such as material chemistry/physics, superconductivity and astrochemistry (Haufler et al., 1990; Pirkle \& Welch, 1991; Sokolov, 1999; Haufler et al., 1990; Yannoni, Johnson, Meijer, Bethune, \& Salem, 1991; Michel, 1992; Yadav \& Kumar, 2008).

One of the most outstanding properties of the $\mathrm{C}_{60}$ molecule is it's high symmetry (Yadav \& Kumar, 2008). There are 120 symmetry operations, like rotations around an axis which maps the molecule onto itself, this make $\mathrm{C}_{60}$ the molecule with the largest number of symmetry operations (Diwan \& Bharadwaj, 2005). As a result of their hard work on the fullerene project, Kroto, H. W., Smalley, R. E. and Curl, R. F. were jointly awarded the prestigious nobel prize in chemistry in the year 1996.

\section{Synthesis of Fullerenes}

Fullerenes were first synthesized through laser vaporization of carbon in an inert atmosphere, but this laser vaporization method produced very small amounts of fullerenes (Unwin, 2004). However large quantities of fullerene $\mathrm{C}_{60}$ were later synthesized through arc heating of graphite and laser irradiation of poly aromatic hydrocarbon (PAHs). Figure. 1 illustrates the main methods for synthesis of fullerenes. 


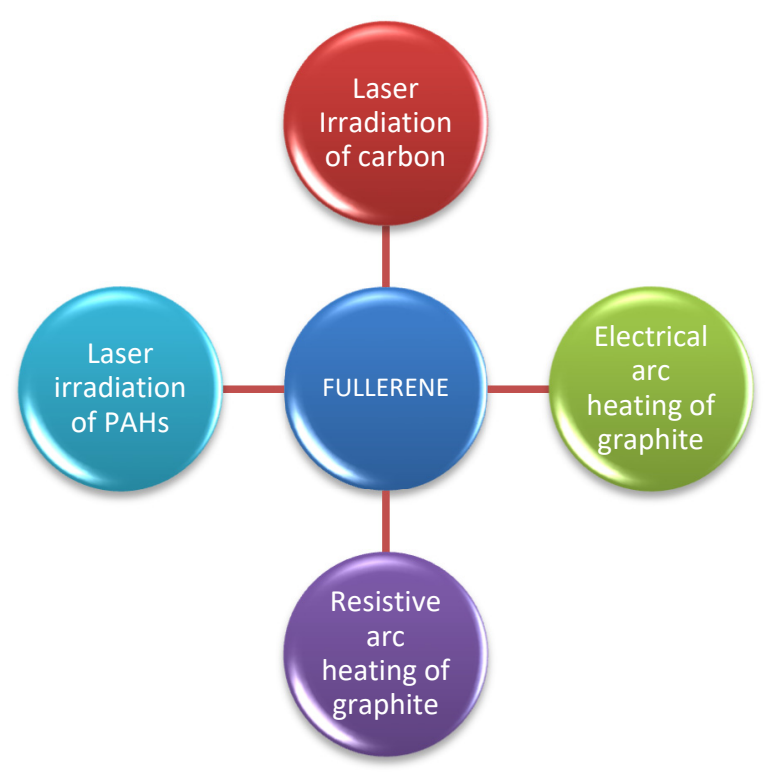

Figure 1. Main synthetic Routes for synthesis of Fullerenes

\subsection{Synthesis by Laser Vaporization of Carbon}

In this method fullerenes are produced in a supersonic expansion nozzle by a pulsed laser which is focused on a graphite target in an inert atmosphere (helium).

This process involves vaporizing carbon from a rotating solid disc of graphite into a high-density helium flow using a focused pulsed laser (Geckeler \& Samal, 1999).

\subsection{Synthesis by Electric arc Heating of Graphite}

This method was conceptualized by Kratchmer and Huttman in 1990. The process involves generating an electric arc between graphite rods in an inert atmosphere which produces a fluffy condensate (Soot) as shown in figure 2 below. A fraction of this fluffy condensate contains the toluene extractible fullerenes. The fullerenes in the soot are then extracted by solvation in a small amount of toluene (Geckeler \& Samal, 1999; Lopez, Mateo-Alonso, \& Prato, 2011), after extraction the toluene (solvent) is removed using a rotary evaporator and the solid mixture made up of mostly $\mathrm{C}_{60}$ with small amount of higher fullerenes is subjected to liquid chromatography Process to obtain pure $\mathrm{C}_{60}$ (Smalley, 1991; Shanboh \& Sundaram, 2015; Curl \& Smalley, 1998; Andrew, 1991).

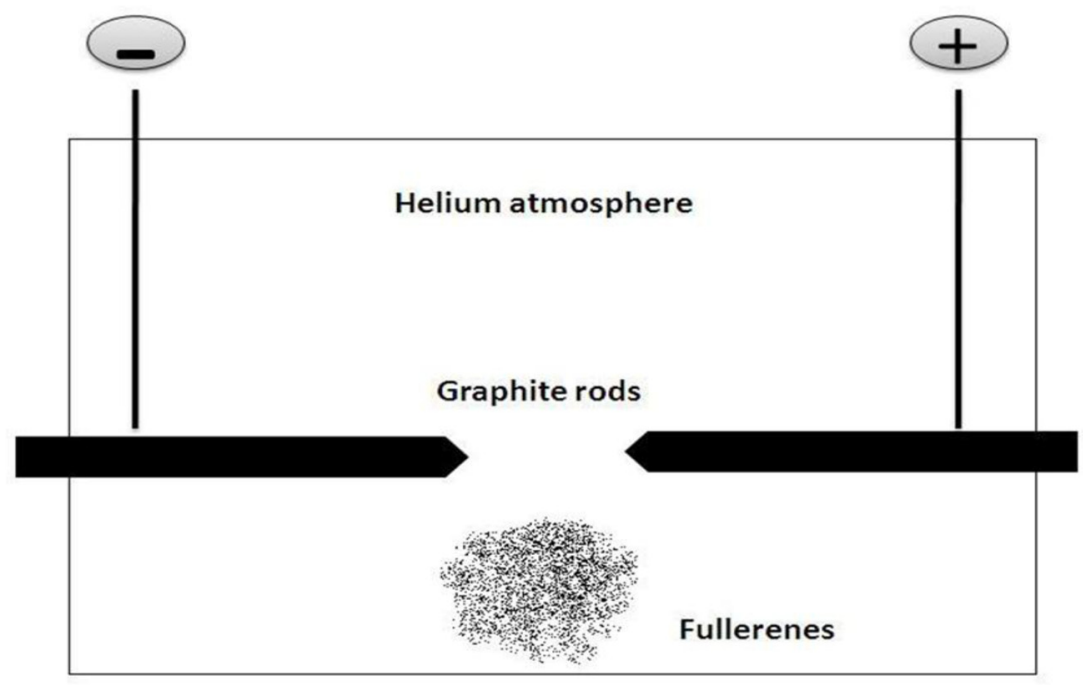

Figure 2. Schematic diagram showing the synthesis of fullerene by arc heating. Reproduced from Shanboh and Sundaram (2015) with permission from Springer Nature 


\subsection{Synthesis by Resistive arc Heating of Graphite}

This method involves the evaporization of carbon rods via resistive heating under partial helium atmosphere; the resistive heating of carbon rods causes the rod to emit a faint grey white plume, soot-like substance made up of fullerenes, and this is collected on glass shields surrounding the carbon rods (Ajie et al., 1990; Baggett, 1991; Haufler et al., 1991).

\subsection{Synthesis by Laser Irradiation of Polycyclic Hydrocarbons (PAHs)}

Direct synthesis of fullerenes has been developed as a means of obtaining new Homologues of the fullerenes family which may not be obtained in good quantity through the uncontrolled process of graphite evaporation. This approach of fullerene synthesis is based on polycyclic aromatic Hydrocarbons (PAHs) that already have the required carbon frameworks. Such PAH molecules are "rolled up" to form fullerenes under flash vacuum pyrolysis (FVP) conditions (Joshipura, 2000; Amsharov, Kabdulov, \& Jansen, 2008), it has been reported that a polycyclic aromatic hydrocarbon which consist of 60 carbon atoms forms fullerene $\mathrm{C}_{60}$ when it is laser irradiated at $337 \mathrm{mn}$ wavelength (Boorum, Vasil'ev, Drewello, \& Scott, 2001) as shown in figure 3.

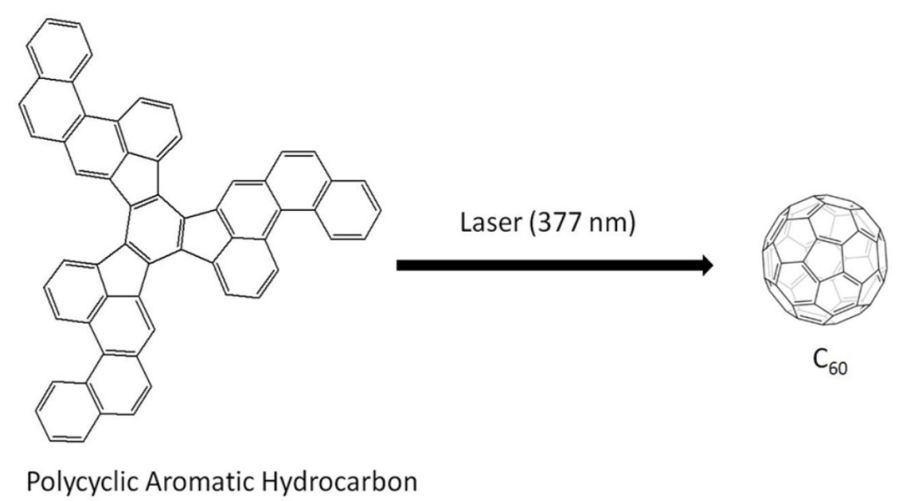

Figure 3. Direct synthesis of fullerene by laser irradiation of PAHs. Reproduced from Shanboh and Sundaram (2015) with permission from Springer Nature

\section{Functionalization of Fullerenes}

The free fullerene molecule cannot be utilized for many applications because of its hydrophobic nature and limited solubility in most solvents (Chiang, Upasani, \& Swirczewski, 1992), thus the chemistry of fullerenes allows the modification of their basic properties in order to be tailored to specific functions because modification causes the molecule to be more reactive and versatile for several applications (Maggini, Scorrano, \& Prato, 1993).

Functionalization can be achieved either through covalent means due to the electrophilic nature of $\mathrm{C}_{60}$ therefore it is an excellent substrate for nucleophilic addition or non-covalent means which include hydrogen bonding, pie-pie interactions and metal ion coordination (Bethune, , Johnson, Salem, De Vries, \& Yannoni, 1993)

Therefore fullerene derivatives can be made to be more lipophilic than the basic fullerene and also water-soluble and amphiphilic too (Hummelen et al., 1995; Weaver et al., 1992; Ciotta et al., 2017; Guo et al., 1992; Wang et al., 1993). Buckminsterfullerene (C60) has been functionalized with Polyvinyl pyrollidone (PVP) to produce a water soluble fullerene derivative (Shanboh \& Sundaram, 2015) as shown in figure 4 below.
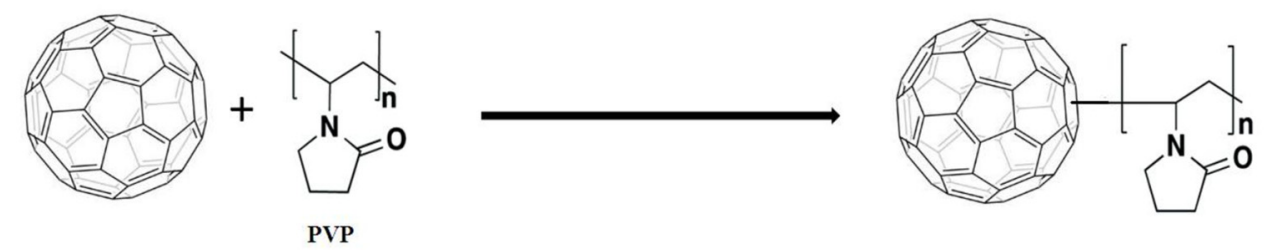

Figure 4. Schematic diagram showing the functionalization of $\mathrm{C}_{60}$ with Polyvinyl pyrollidone (PVP). Reproduced from Shanboh and Sundaram (2015) with permission from Springer Nature 


\section{Structure and Reactivity of Fullerenes}

The electronic structure of fullerenes is a very critical factor which determines their exceptional chemical properties (Mauter \& Elimelech, 2008). Each carbon atom of a fullerene is linked to three neighboring carbon atoms on the vertex of a polyhedron, therefore it forms two single bonds and one double bond (Sokolov, 1999). Figure 5 shows the basic structure of most abundant fullerene (buckminsterfullerene).

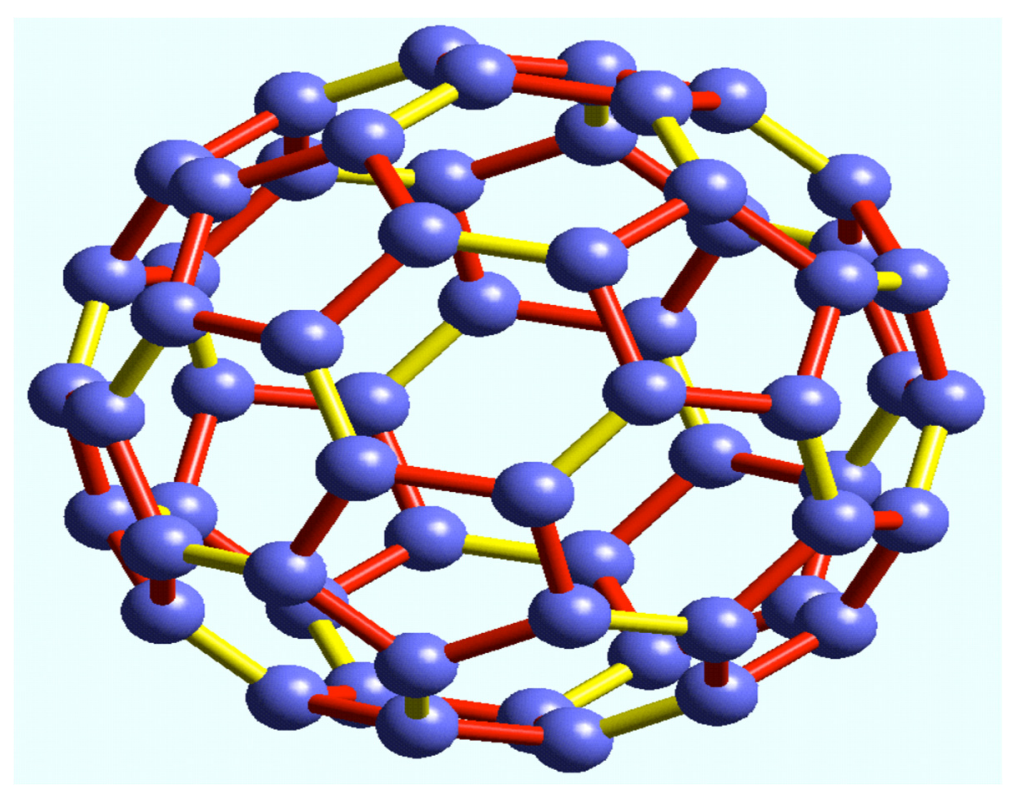

Figure 5. The Molecular structure of $\mathrm{C}_{60}$ Buckminsterfullerene (Ulloa, 2013)

There are two types of bonds in a $\mathrm{C}_{60}$ fullerene namely; a bond shared between a hexagon and pentagon (6.5) which behaves like single bond and that which is shared between two hexagon (6.6) which behaves like a double bond, these bonds coats the whole surface of any fullerenes with a system of conjugated double bonds. Fullerene structures with fewer hexagons exhibit greater $\mathrm{SP}^{3}$ bonding characteristics such as higher strain and more reactive carbon sites while those with adjacent pentagons usually show lower stability and relative abundance than fullerene with isolated pentagon, where there is obvious delocalization of $\pi$ (pie) bonds over the structure (Kroto, 1987; Campbell, Fowler, Mitchell, \& Zerbetto, 1996; Taylor \& Walton, 1993). The surface of a fullerene is curved therefore it is natural to have pyramidalized carbon atoms, and pyramidalization changes the hybridization of atomic orbitals at the carbon atoms so that $\pi$ (pie) orbitals contain different parts of S and P orbitals which paves the way for various chemical activities (Hirsch, 1998; Payne, Teter, Allan, Arias, \& Joannopoulos, 1992).

The conjugated pie $(\pi)$ - system in fullerenes is not like that found in classical aromatic compounds because there are no replaceable hydrogen atoms that could facilitate substitution reactions (Hirsch, 199). The interaction between a carbon atom and an external chemical reagent could lead to either of the following: orbital / hybrid changing towards $\mathrm{SP}^{3}$, pie $(\pi)$ bond breaking or reaction between the free pie $(\pi)$ - orbital and the external chemical reagent (Park, Srivastava, \& Cho, 2001). There are two main chemical transformations that happen in fullerenes, namely addition reactions that leads to the formation of exohedral adducts and redox reactions that lead to the formation of salts.

Irrespective of their extreme conjugation fullerenes behave as electron-deficient alkenes (Da Ros, Prato, Novello, Maggini, \& Banfi, 1996) because they add nucleophiles, homolytic reagents and even free radicals to produce stable adducts (Sokolov, 1999).

Reports have shown that fullerenes $\left(\mathrm{C}_{60}\right.$ and $\left.\mathrm{C}_{70}\right)$ have been successfully oxidized through photo oxidation, electrochemical oxidation, dimethyldioxirane addition and ultrasound induced oxidation (Wood et al., 1991; Creegan et al., 1992; Taylor et al., 1995; Hamano, Mashino, \& Hirobe, 1995; Heymenn \& Chibante, 1993; Hirsch, 1997; Bae-Ko \& Nam-Baek, 2002). 
Fullerenes are unique because they represent carbon in the soluble form, which makes it possible for the preparation of carbon films in solutions.

An assessment of the solubility of $\mathrm{C}_{60}$ as a function of solvent properties such as dielectric constant, index of refraction, molecule size and hydrogen bonding strength confirms the "like dissolving like" principle (Rouff, Tse, Malhotra, \& Lorent, 1993). Since they are non-polar fullerene are hydrophobic thus are soluble in non-polar solvent such as hydrocarbons mostly aromatic hydrocarbons and carbon disulfide.

Substitution with electron donating groups such as methyl and methoxy groups increases solubility while substitution with electron withdrawing group such as nitro and nitrile reduces solubility (Reichardt, 1990).

\section{Applications of Fullerene}

The unique physical and chemical properties of fullerenes has led many researchers to explore the application of this molecule and it's functionalized derivatives in various areas such as medicine, photovoltaics, gas adsorption/storage, pharmaceuticals just to mention a few.

\subsection{Medical Application}

Size, Hydrophobicity, electronic configuration and three - dimension ability are some of the most alluring characteristic of fullerene which has brought them to the front burner of medical chemistry. In spite of obvious solubility challenges their exceptional carbon cage structure and vast scope for functionalization make fullerenes standout as potential therapeutic agents (Fowler, \& Ceulemans, 1995; Iwamoto \& Yamakoshi, 2006; Hetzer, 1997; Friedman, Decamp, \& Sijbesma, 1993).

\section{a. Antioxidant/Biophamaleuticals}

Fullerenes react readily with free radicals because of the presence of large amounts of conjugated double bonds and low lying Lowest Unoccupied Molecular Orbitals (LUMO), it has been reported that about 34 methyl radicals have been added onto a single $\mathrm{C}_{60}$ molecules as such it is considered the world's most efficient radical Scavenger (Friedman, Decamp, \& Sijbesma, 1993; Krusic et al., 1991; Gharbi, Pressac, \& Hadchouel, 2005; Halliwel, 1992).

\section{b Antibacterial/Antimicrobial Activity}

Hydrophilic fullerene derivatives such as fullerols and amino fullerene have shown antibacterial activities, as such have attracted attention for possible application in water treatment systems (Kang, Mauter, \& Elimelech, 2009; Lyon, Adams, Faulkner, \& Alvarez, 2006; Fortner et al., 2005). Reports have also shown that attachment of multiple, hydroxyl, carboxylic acid, and glycolic oxide on $\mathrm{C}_{60}$ instigates photodynamic cycotoxicitly against pathogenic microorganisms including multi-antibiotic-resistant bacteria (Yamakoshi et al., 2003; Thota et al., 2012). The biocidal activity of $\mathrm{C}_{60}$ is been mostly attributed to it's ability to generated reactive oxygen species (ROS) such as singlet oxygen and superoxide through photosensitization when it interacts with organic solvents (Das et al., 2017; Arbogast, Foote, \& Kao, 1992; Barkry et al., 2007).

\section{c. Antiviral Activity}

Antiviral potentials exhibited by fullerene derivatives have been linked to their matchless molecular cage structure and antioxidant property (Subesma et al., 1993). An investigation revealed that fullerene derivatives could restrain and form a complex with HIV protease (Barras, Khanal, \& Boukheroub, 2015). Reports have also shown that, fulleropyrolidines bearing two amino groups were active against HIV - I and HIV - 2 (Moussa, Pressac, \& Hadchouel, 1997).

\section{d. Diagnostics}

When a metal ion is inserted into a fullerene cage an endofullerene is formed and this endohedral metallofullerene cage could serve as an isolation chamber which separates reactive atoms from the biological environment (Dorn \& Fatourus, 2010). One rapidly emerging application of endohedral metallofullerene (EMFs) is the gadolinium encapsulated EMFs which have been announced as top candidates for next generation magnetic resonance imaging (MRI) contrast agents (Baba, 2006; Toth, 2012; Thras et al., 1999). Biodistribution studies have also revealed the localization of metallofullerols to microphages therefore leading to an important conclusion that there species are selectively targeted to tissues rich in microphage and might be very valuable chemotherapic agents for treatment of bone cancer and leukemia (Azzam \& Domb, 2004).

\section{e. Drug Delivery}

Fullerenes can be made to be potential drug carriers for cellular delivery because of their good biocompatibility, selective targeted delivery and controlled release of carried drugs. By attaching hydrophilic species on them, fullerenes become water soluble, as such they become exceptional in drugs and gene cellular delivery (Foley et al., 
2002; Isobe, Nakanishi, Tomita, Jinno, Okayama, \& Nakamura, 2006). Since functionalized fullerenes can cross cell membranes and bind with mitochondria they can be regulated to deliver drugs slowly in order to achieve maximum thereupatic results. Investigations have shown that DNA-functionalized fullerenes exhibit very remarkable effectiveness when compared to commercially available lipid-based vectors (Isobe, Tomita, Jinno, Okayama, \& Nakmura, 2001; Makamura \& Isobe, 2003; Bottary, Swanzes, Trukhina, \& Torres, 2011).

\subsection{Photovoltaics}

Owing to excellent electron accepting capacity and low reorganization energies which aids electron transfer processes, fullerenes are been used as major components in artificial photosynthetic processes (Guldi \& Prato, 2000; Echegoyen \& Echegoyen, 1998; Troshin et al., 2007).

Fullerene have found profound usefulness in photovoltaic devices, organic electronics and photo catalysis (Lebedeva et al., 2016) because they combine with suitable electron donor components to form donor-acceptor (D-A) dyads that can generate long-lived charge separated states (Villegas et al., 2011).

Some organic and transition metal containing electron donating units that have been linked to fullerene cages include; metalloporphyrins, cyanines, phythalocyanines, Ruthenium bipyindi complexes, boron-dipyrins, metallocenes and tetrathiafulvalenes (Bottari, Kahnta, Guldi, D. \& Torres, 2013; Maggini et al., 1998; Bandi et al., 2013; Martin, Sánchez, Herranz, \& Guldi, 2000; Guldi, Maggini, Scorrano, \& Prato, 1997; Kanev, Nenova, \& Koprinarov, 2006).

Investigations have shown that the performance of polymer transistors such as Organic Field Effect Transistors (OFTETS) and photo detectors is on the increase due to the existing synergy between organic photovoltaics (OPVs) and organic field effect transistors (OFETS).

Consequently fullerenes have found usefulness in photoelectric devices, electrochemical materials, doping impurity for conductive polymer films, gas sensors and superconductors (Hoppe, Arnold, Meissner, \& Sariciftci, 2004; Riedel \& Dyakonov, 2004; Wang, Guo, Fu, Wu, \& Zhu, 2004; Sisk, Kang, Raja, \& Farahi, 1997; Hayashi, Yamamoto, Suzuki, \& Matsuoka, 2004; Liu, Bunker, \& Sun, 1996).

\subsection{Fullerene-Based Polymeric Materials}

The formation of fullerene-based polymeric materials and their subsequent application in various spheres of endeavor is because of their exceptional electronic properties (Wijnkoop et al., 1997) fullerene-based polymeric materials are produced in a number of ways either by regular attachment of fullerene materials to a polystyrene in friedel-crafts type reactions or indirect linkage of fullerenes $\mathrm{C}_{60}$ with spacer groups such as $\mathrm{Pt}(\mathrm{dba})_{2}, \mathrm{Pd}_{2}$ $(\mathrm{dba})_{3} . \mathrm{CHCl}_{3}$ or $\mathrm{Pt}(\mathrm{cad})_{2}$. (Where dba represents dibenzylideneacetone and cad represents cycloocta-1, 5-diene), the reaction of fullerene $\mathrm{C}_{60}$ with either of these spacer groups results in the displacement of the ligands (dba or cad) to form insoluble $\mathrm{PtC}_{60}$ (Nagashima et al., 1993; Fedurco, Costa, Balch, \& Fawcett, 1995; Alvarez, Wilson, Mackeyev, \& Lee, 2009). These redox-active fullerene based polymers can also be produced by electrochemical reduction of fullerenes under cathodic conditions, here they are usually formed or produced as polymer films on an electrode when $\mathrm{C}_{60} \mathrm{O}$ is reduced (Pyrzynska, 2007).

\subsection{Water Purification/Environment}

Inspite of it's well known photocatalytic potential low solubility in water of the most abundant fullerene $\left(\mathrm{C}_{60}\right)$, it's low stability in water is a major setback for water purification and environmental applications. An study revealed that functionalizing $\mathrm{C}_{60}$ with hydrophilic moieties produces a material that can inactivate pathogenic microorganism via photo catalytic processes (Brunet et al., 2009). The potential for fullerenes to act as adsorbents for organic compounds has been investigated and also applied in speciation analysis of different forms of a metal (Snow, Park, \& Kim, 2014).

The effective production of reactive oxygen species (ROS) by photosynthetic fullerene derivatives (Aminofullerene and fullerols) promises to pave the way for the development of $\mathrm{C}_{60}$-fullerene mediated oxidation processes which could be very valuable for water disinfection (Hofman et al., 2010; Burakov et al., 2018).

\subsection{Hydrogen Storage}

One unique characteristic of fullerenes which makes them ideal storage molecules for hydrogen is the hydrogenation of their $\mathrm{C}-\mathrm{C}$ bonds to form $\mathrm{C}-\mathrm{H}$ bonds which actually possess lower bond energies therefore heating breaks the $\mathrm{C}-\mathrm{H}$ and reverts the molecule back to its original distinctive fullerene structure. Thus-fullerenes are able to retain a maximum of $6.1 \%$ of hydrogen due to their chemistry and cage molecular structure (Shanboh \& Sundaram, 2015; Vidyaev, Savostikov, Boretsky, \& Verkhorubov, 2016). 


\subsection{Energy Materials}

Surface electrodes of super capacitors are usually made of a conductive layer of carbon and their capacitance is mostly dependent on surface area, pore size distribution, accessibility of electrolyte and electrical conductivity ( $\mathrm{Li}$ $\&$ Wei, 2013). However, poor accessibility of electrolyte to solid surfaces usually results in low capacitance (Genc et al., 2017), thus nanotechnology has opened up new openings via the use of a wide range of carbon based nano materials all in a bid to surmount the aforementioned inadequacies (Yu, Tetard, Zhai, \& Thomas, 2015).

\section{a. Super capacitors}

Recent research investigations have shown that hybrid nano materials can generate synergistic and more exciting performance as electrode materials than the impact achieved by individual nano materials (Shen et al., 2011). A recent study revealed that a hybrid system composed of fullerene and graphene molecules conveyed a specific capacitance of $135.36 \mathrm{Fg}^{-1}$ when used as electrode for super capacitors in contrast to the specific capacitance of pure graphene electrode $\left(101.88 \mathrm{Fg}^{-1}\right)$. According to the report the fullerene / graphene composite also exhibited a good retention time rate of $92.35 \%$ after 1000 charge / discharge circles (Ma, Guo, Gao, \& Qin, 2014).

\section{b. High - performance lithium ion batteries}

Carbon based materials are used as anodes in lithium -ion batteries because carbon provides safety and more longer cycle life (Sato, Idiom, Suzuki, \& Fujimoto, 1992). A high-performance anode material based on hydrogenated fullerenes in lithium-ion rechargeable batteries was investigated by a team of researchers. Results from the study reveal that application of hydrogenated fullerenes as additives to commercial graphite resulted in extraordinary reduction of the irreversible capacity of commercial carbon with an increase in its reversible capacity too (Loufty \& Katagiri, 2002).

\section{c. Super conductor materials}

Studies have shown that when an alkali metal is embedded within the voids of fullerene $\mathrm{C}_{60}$, the new composite formed becomes a super conductor (Wang et al., 2015). Accordingly, it has been reported that $\mathrm{K}_{3} \mathrm{C}_{60}$ composite posses high super conducting critical temperature with almost a perfect 3-D superconductivity, current density, ductility and high stability (Qi, Tao, Wand, \& Xue, 2018).

\subsection{Reinforced Composites}

The utilization of carbon based nano materials as reinforcement has been widely acknowledged as an effective means of enhancing the mechanical properties of infrastructure materials (Lu, Xie, Feng, \& Zhong, 2015). The effect of reinforcing Al-Mg alloy with $\mathrm{C}_{60}$ has been reported, with the resultant Aluminum -matrix composite exhibiting good malleability, thermal stability and enhanced mechanical properties (Perfilove, Evodokimov, Pozdnjakov, \& Blank, 2015).

\section{Conclusion/Future Perspective}

Fullerenes were initially found to be inert molecules but their unique cage structure and solubility in organic solvents revealed their susceptibility to exodehedral and endohedral functionalization. Addition reactions lead to the formation of exohedral adducts while Redox reactions produced endohedral adducts including polymer films. Proper understanding of the principles governing the functionalization of the most abundant fullerene $\left(\mathrm{C}_{60}\right)$ remains the main pivot to the ever expanding openings available for the utilization of this third allotrope of carbon. More research efforts should be made in the application of functionalized fullerenes in methane storage, catalysis and environmental studies.

\section{Acknowledgement}

The authors declare that there is no conflict of interest regarding the publication of this paper.

\section{References}

Ajie, H., Alvarez, M. M., Anz, S. J., Beck, R. D., Diederich, F., Fostiropoulos, K., ... \& Rubin, Y. (1990). Characterization of the soluble all-carbon molecules C60 and C70. Journal of Physical Chemistry, 94(24), 8630-8633.

Alvarez, P., Wilson, L., Mackeyev, Y., \& Lee, J. (2009). Novel photocatalytic fullerenes for water and wastewater treatment and disinfection.

Amsharov, K., Kabdulov, M., \& Jansen, M. (2008). Direct synthesis of fullerenes. Max Plank institute of solid state research, Stuttgart, Abteilung Jansen. 
Anderson, J. L., West, M. A., \& Foote, C. S. (1997). Extraction, Isolation, and Characterization of Fullerene C60: A Safe and Reliable Separation Experiment. Journal of chemical education, 74(3), 311.

Andrew, M. (1991). Fullerene chemistry. Chemistry and Industry, 346.

Arbogast, J. W., Foote, C. S., \& Kao, M. (1992). Electron transfer to triplt fullerene C60. J. Am. Chem. Soc., 114, 2277-2279.

Azzam, T., \& Domb, A. J. (2004). Current developments in gene transfection agents. Curr. Drug. Del., 1, 165193.

Baba, Y. (2006). Nano biodevices for biomedical applications. Nanomedicine, Nanotecnology biology and medicine, 2, 306.

Bae-Ko, W., \& Nam-Baek, K. (2002). The oxidation of fullerenes $\left(\mathrm{C}_{60}\right.$ and $\left.\mathrm{C}_{60}\right)$ with various oxidants by ultrasonication. Phys. Sol. Stat., 44, 424-426.

Baena, J. R., Gallego, M., \& Valcarcel, M. (2002). Fullerenes in the analytical sciences. TrAC Trends in Analytical Chemistry, 21(3), 187-198.

Baggett, J. (1991). Great balls of carbon. New scientist, 34-38.

Bandi, V., El-Khouly, M. E., Ohkubo, K., Nesterov, V. N., Zandler, M. E., Fukuzumi, S., \& D'Souza, F. (2013). Excitation-Wavelength-Dependent, Ultrafast Photoinduced Electron Transfer in Bisferrocene/BF2-ChelatedAzadipyrromethene/Fullerene Tetrads. Chemistry-A European Journal, 19(22), 7221-7230.

Barkry, R., Vallant, R. M., Najam-Ul, H., Rawer, M., Szabo, Z., Huck, C. Y., \& Bonn, G. K. (2007). Medicinal applications of fullerenes. Inter. J. NANOMED., 2, 639-649.

Barras, A., Khanal, M., \& Boukheroub, R. (2015). Nano structures for the inhibition of viral infections. Molecules, 20, 1051-14081.

Bethune, D. S., Johnson, R. D., Salem, J. R., De Vries, M. S., \& Yannoni, C. S. (1993). Atoms in carbon cages: the structure and properties of endohedral fullerenes. Nature, 366(6451), 123-128.

Bochvar, D. A., \& Galpern, E. G. (1973). Hypothetical systems-carbododecahedron, s-icosahedrone and carbo-sicosahedron. Doklady Akademii Nauk Sssr, 209(3), 610-612.

Boorum, M. M., Vasil'ev, Y. V., Drewello, T., \& Scott, L. T. (2001). Groundwork for a rational synthesis of C60: cyclodehydrogenation of a C60H30 polyarene. Science, 294(5543), 828-831.

Bottari, G., Kahnta, A., Guldi, D. M., \& Torres, T. (2013). Protonoted induced changes in the photo physical properties of a phthalocyanine and a covalently linked phthalocyanine- $\mathrm{C}_{60}$ fullerene dyad. ECS. J. Solid State Sci. Technol., 2, m3145-m3150.

Bottary, G., Swanzes, J. A., Trukhina, O., \& Torres, T. (2011). Phthalocyanine-carbon nanostructure materials assembled through Supramolecular interactions. J. Phys. Chem. Lett., 2, 905-913.

Brunet, L., Lyon, D. Y., Hotze, E. M., Alvarez, P. J. J., \& Weisner, M. R. (2009). Comparative photoactivity and antibacterial properties of $\mathrm{C} 60$ fullerenes and titanium dioxide nanoparticles. Environ. Sci. Technol., 43, 4355-4360.

Burakov, A. E., Galunin, E. V., Burakov, I. V., Kucherova, A. E., Agarwal, S., Tkachev, A. E., \& Gupta, V. K. (2018). Adsorption of heavy metals on conventional and nanostructured materials for water treatment purposes: A review. Ecotoxicology and Environmental Safety, 148, 702-712.

Campbell, E. E., Fowler, P. W., Mitchell, D., \& Zerbetto, F. (1996). Increasing cost for Pentagon adjacency for higher fullerenes. Chem. Phys., Lett., 250, 544-458.

Carey, A. F. (2003). Organic Chemistry (5 ${ }^{\text {th }}$ ed.). McGraw-Hill Education.

Chiang, L. Y., Upasani, R. B., \& Swirczewski, J. W. (1992). Versatile nitronium chemistry for C60 fullerene functionalization. Journal of the American Chemical Society, 114(26), 10154-10157.

Ciotta, E., Prosposito, P., Tagliatesta, P., Lorecchio, C., Venditti, I., Fratoddi, I., \& Pizzoferrato, R. (2017, August). Sensitivity to Heavy-Metal Ions of Cage-Opening Fullerene Quantum Dots. In Multidisciplinary Digital Publishing Institute Proceedings (Vol. 1, No. 4, p. 475).

Creegan, K. M., Robbin, W. K., Millar, J. M., Sherwood, R. D., Tindall, P. J., Cox, D. M., ... Jines, D. R. (1992). Synthesis and characterization of $\mathrm{C}_{60} \mathrm{O}$, the first fullerene epoxide. J. Am. Chem., 114, 1103-1105.

Curl, R. F., \& Smalley, R. E. (1998). Probing C60. Science, 242, 1017-1022. 
Da Ros, T., Prato, M., Novello, F., Maggini, M., \& Banfi, E. (1996). Easy access to water soluble fullerene derivative via 1,3-dipolar cycloadditions of azomethine ylides to $C_{60}$.J. Organic. Chem., 61, 9070-9072.

Das, R., Vecitis, C. D., Schulze, A., Cao, B., Ismail, A. F., Lu, X., ... \& Ramakrishna, S. (2017). Recent advances in nanomaterials for water protection and monitoring. Chemical Society Reviews, 46(22), 6946-7020. 001:10.1039/c6c00921b, 39-40

Davidson, R. A. (1981). Spectral analysis of graphs by cyclic automorphism subgroups. Theoretica chimica acta, 58(3), 193-231.

Diwan, P., \& Bharadwaj, A. (Eds.). (2005). The Nanoscope: Encyclopedia of Nanoscience and Nanotechnology. Pentagon Press.

Dorn, H. C., \& Fatourus, P. P. (2010). Endohedral metallofullerenes: Applications of new class of carbonaceous nano materials. Nanotechnology Letters, 2. 65-72.

Dresselhaus, M. S., Dresselhaus, G., \& Eklund, P. C. (1996). Science of fulluerenes and carbon nanaotubes. Academic Press New York.

Echegoyen, L., \& Echegoyen, L. E. (1998). Electrochemistry of fullerenes and their derivatives. Acc. Chem. Res., 31, 593-601.

Fang, P. F., Zeng, Z. R., Fan, J. H., \& Chen, Y. Y. (2000). Synthesis and characteristics of [60] fullerene polysiloxane stationary phase for capillary gas chromatography. Journal of Chromatography A, 867(1-2), 177-185.

Fedurco, M., Costa, D. A., Balch, A. L., \& Fawcett, W. R. (1995). Electrochemical synthesis of a redox-active polymer-based on buckminster fullerene epoxide. Angew.Chem. Int. Ed., 34, 194-196.

Foley, S., Coley, C., Monique, S., Claude, B., Bennard, F. E., Patrick, S., \& Christian, L. (2002). Cellular localization of water based fullerene derivative. Biochembiophys. Res. Commun., 294. 116-119.

Fortner, J. D., Lyon, D. Y., Sayes, C. M., Boyd, A. M., Falkner, J. C., Horze, E. M., ... Hughes, J. B. (2005). C60 in water: Nano crystal formation and microbial response. Environ. Sc. Technol., 39, 4307-4316.

Fowler, P. W., \& Ceulemans, A. (1995). A highly water soluble $\mathrm{C}_{60}$ - NVP Copolymer: Electron deficiency of the fullerenes. J. Phys. Chem., 99, 508-510.

Friedman, S. H., Decamp, D. L., \& Sijbesma, R. P. (1993). Inhibition of the HIV-1 Protease by fullerene derivative: Model building studies and environmental verification. J. Am. Chem. Soc., 115.

Geckeler, K. E., \& Samal, S. (1999). Syntheses and properties of macromolecular fullerenes, a review. Polymer international, 48(9), 743-757.

Genc, R., Alas, M. O., Harputlo, E., Repp, S., Kremer, N., Castellano, M., ... Erdem, E. (2017). Scientific Reports, 7, 11222, 1-13.

Gerhardt, P., Löffler, S., \& Homann, K. H. (1987). Polyhedral carbon ions in hydrocarbon flames. Chemical physics letters, 137(4), 306-310.

Gharbi, N., Pressac, M., \& Hadchouel, M. (2005). [60]fellerene is a powerful antioxidant in vivo with acute or sub-acute toxicity. Nano. Lett., 5, 2578-2585.

Guillaume, Y. C., Peyrin, E., \& Grosset, C. (2000). C60 and C70 HPLC retention reversal study using organic modifiers. Analytical chemistry, 72(6), 1301-1306.

Guldi, D. M., \& Prato, M. (2000). Ecited state properties of $\mathrm{C}_{60}$ fullerene derivatives. Acc. Chem. Res., 31, 593601.

Guldi, D. M., Maggini, M., Scorrano, G., \& Prato, M. (1997). Intramolecular Electron Transfer in Fullerene/Ferrocene Based Donor- Bridge- Acceptor Dyads. Journal of the American Chemical Society, $119(5), 974-980$.

Guo, T., Diener, M. D., Chai, Y., Alford, M. J., Haufler, R. E., McClure, S. M., ... \& Smalley, R. E. (1992). Uranium stabilization of C28: a tetravalent fullerene. Science, 257(5077), 1661-1664.

Halliwel, B. (1992). Reactive oxygen species and the central nervous system. J. Neurochem, 59, 1609-1623.

Hamano, T., Mashino, T., \& Hirobe, M. (1995). Oxidation of [60] fullerene by cytochrome P450 chemicalmodels. J. Chem. Soc. Commun., 0, 1537-1538. 
Haufler, R. E., Chai, Y., Chibante, L. P. F., Canceicao, J., Jin, C., Wang, L-S., ... Smalley, R. E. (1991). Arch generation of $\mathrm{C}_{60}$. Mat. Res. Sco. Symp. Proc., 260, 627-637.

Haufler, R. E., Chai, Y., Chinabel, P. F., Conceicao, J., Changming, J., Lai-Shen, W., ... Smalley, R. E. (1990). Mat. Res. Soc. Symp. Proc. Boston.

Haufler, R. E., Conceicao, J., Chibante, L. P. F., Chai, Y., Byrne, N. E., Flanagan, S., ... \& Pan, C. (1990). Efficient production of C60 (buckminsterfullerene), C60H36, and the solvated buckide ion. Journal of Physical Chemistry, 94(24), 8634-8636.

Hayashi, A., Yamamoto, S., Suzuki, K., \& Matsuoka, T. (2004). The first application of polymer-like materials, $\mathrm{C}_{60} \mathrm{Pd}_{\mathrm{n}}$, as gas adsorbents. $R \& D$ Review of Toyota $C R D L, 40,14-21$.

Heath, R. J. (2016). Harry Kroto, Discoverer of new form of carbon. Nature, 533, 470.

Hetzer, S. (1997). Fullerenes in membranes, structural and dynamic effects of lipophilic $C_{60}$ derivatives in phospholipids bilayer.

Heymenn, D., \& Chibante, L. F. P. (1993). Photo transformation of $\mathrm{C}_{60}, \mathrm{C}_{70}, \mathrm{C}_{60} \mathrm{O}$ and $\mathrm{C}_{60} \mathrm{O}_{2}$. Chem. Phy. Lett., 207, 339-342.

Hirsch, A. (199). Principles of fullerene reactivity. Topics in current chemistry.

Hirsch, A. (1997). Aspects of organic chemistry of fullerenes. J. Phys. Chem. Soc., 58, 1729-1740.

Hirsch, A. (1998). Topics in current chemistry.

Hofman, C. C., Lindner, S. M., Ruppert, M., Hirsch, A., Hague, S. A., Thelakkat, M., \& Kohler, J. (2010). The influence of $\pi-\pi$ on the harvesting properties of perylene bisimide antennas that are covalently linked to a [60] fullerene. Royal Society of chemistry (supplementary material) for PCCP, 1-2.

Hoppe, H., Arnold, N., Meissner, D., \& Sariciftci, N. S. (2004). Modelling of optical absorption in conjugated polymer / fullerene bulk-heterojunction plastic solar cells. Thin solid films, 451-452, 589-592.

Howard, J. B., McKinnon, J. T., Makarovsky, Y., Lafleur, A. L., \& Johnson, M. E. (1991). Fullerenes C60 and C70 in flames. Nature, 352(6331), 139.

Howard, J. B., McKinnon, J. T., Makarovsky, Y., Lafleur, A. L., \& Johnson, M. E. (1991). Fullerenes C60 and C70 in flames. Nature, 352(6331), 139-141.

Hummelen, J. C., Knight, B. W., LePeq, F., Wudl, F., Yao, J., \& Wilkins, C. L. (1995). Preparation and characterization of fulleroid and methanofullerene derivatives. The Journal of Organic Chemistry, 60(3), 532538 .

Iijima, S. (1980). Direct observation of the tetrahedral bonding in graphitized carbon black by high resolution electron microscopy. Journal of Crystal Growth, 50(3), 675-683.

Isobe, H., Nakanishi, W., Tomita, N., Jinno, S., Okayama, H., \& Nakamura, E. (2006). Structural requirement for efficient transfection. Chemistr-an Asian Journal, 1, 167-175.

Isobe, H., Tomita, N., Jinno,S., Okayama, H., \& Nakmura, E. (2001). Synthesis and transfection capability of multifunctionalized fullerene polyamine. Chem. Lett., 12, 1214-1215.

Iwamoto, Y., \& Yamakoshi, Y. (2006). Apotential material for photodynamic therapy. Chem. Commun., 46, 48054807.

Jinno, K., Tanabe, K., Saito, Y., \& Nagashima, H. (1997). Separation of Polycyclic Aromatic Hydrocarbons with Various C 60 Fullerene Bonded Silica Phases in Microcolumn Liquid Chromatography. Analyst, 122(8), 787791.

Jones, D. E. H. (1966). Ariadne. New Scientist, 32(245), 1.

Joshipura, K. N. (2000). Exploring the fullerenes - How geometric ideas explain strange fullerene structures. Resonance, 5, 92-98.

Kanev,S., Nenova, Z., \& Koprinarov, N. (2006). Photoabsorption and photoconductivity in $\mathrm{C}_{60}$ layers. Semiconductor. Physics. Quantum. Electronics and optoelectronics, 9. 21-25.

Kang, S., Mauter, M. S., \& Elimelech, M. C. (2009). Microbial cycotoxicity of carbon-based nanomaterials: Implications for the river water and waste water effluent. Environ. Sci.technon., 43, 2684-2653.

Krato, H. W., \& Heath, J. R. (1985). O'Brien, SC, Curl, RF \& Smalley, RE. Nature, 318, 162-163. 
Krätschmer, W., Lamb, L. D., Fostiropoulos, K., \& Huffman, D. R. (1990). Solid C60: a new form of carbon. Nature, 347(6291), 354-358.

Krätschmer, W., Lamb, L. D., Fostiropoulos, K., \& Huffman, D. R. (1990). Solid C60: a new form of carbon. Nature, 347(6291), 354.

Kroto, H. (1988). Space, stars, C60, and soot. Science, 242(4882), 1139-1145.

Kroto, H. (1997). Symmetry, space, stars, and C60 (Nobel lecture). Angewandte Chemie International Edition, 36(15), 1578-1593.

Kroto, H. W. (1982). Tilden Lecture. Semistable molecules in the laboratory and in space. Chemical Society Reviews, 11(4), 435-491.

Kroto, H. W. (1987). Stability of the fullerenes $\mathrm{C}_{24} \mathrm{C}_{28} \mathrm{C}_{32} \mathrm{C}_{36} \mathrm{C}_{50} \mathrm{C}_{60}$ and $\mathrm{C}_{70}$. Nature, 329, 529-531

Kroto, H. W. (1987). The stability of the fullerenes Cn, with $\mathrm{n}=24,28,32,36,50,60$ and 70. Nature, 329(6139), 529-531.

Kroto, H. W. (1992). C60: Buckminsterfullerene, the celestial sphere that fell to earth. Angewandte Chemie International Edition, 31(2), 111-129.

Kroto, H. W. (1993). Electronic properties of fullerenes. Springer series in solid-state sciences., 17, 1-2.

Kroto, H. W., Heath, J. R., O’Brien, S. C., Curl, R. F., \& Smalley, R. E. C. (1993). Buckminsterfullerene. Nature, $318,162-163$.

Kroto, H.W., Allaf, A. W., \& Balm, S. P. (1991). C 60 : Buckminsterfullerene. Chem. Rev., 9., 1213-1235.

Krusic, P. J., Wassermen, E., Keizer, P. N., Morton, J. R., \& Preston, K. F. (1991). Radical reactions of C 60. Science, 254, 1183-1185.

Lebedeva, M. A., Chamberlain, T. W., Scattergood, P. A., Delor, M., Sazanovich., I. V., Davies, E. S., Suyetin, M., Besley, E., Schroder, M., Weinstein, J. A., \& khlobystov, A. N. (2016). Stabilizing the lowest chargeseparated state in a metal chromophore-fullerene assembly: A tunable panchromatic absorbing donoracceptor triad. Chem. Sci., 7, 5908-5921.

Li, X., \& Wei, B. (2013). Supercapacitors based on nanostructured carbon. Nano Energy, 2, 159-173.

Liu, B., Bunker, C. E., \& Sun, Y. P. (1996). Preparation and characterizationof soluble pendant [60] fullerenepolystyrene. Chem. Commun, 0, 1241-1242.

Lopez, A. M., Mateo-Alonso, A., \& Prato, M. (2011). Materials chemistry of fullerene C 60 derivatives. Journal of Materials Chemistry, 21(5), 1305-1318.

Loufty, R. O., \& Katagiri, S. (2002). Fullerene materials for lithium-ion battery applications. Perspectives of fullerene nanotechnology, 357-367.

Lu, S. N., Xie, N., Feng, L. C., \& Zhong, J. (2015). Applications of nanostructured carbon materials in constructions: The state of the art. Journal of Nanomaterials, 2015, 6.

Lyon, D. Y., Adams, L. K., Faulkner, J. C., \& Alvarez, J. J. (2006). Anti bacterial activity of fullerene water suspension: Effects of preparation methods and particle size. Environ. Sc. Technol., 40, 4360-4366.

Ma, J., Guo, Q., Gao, H. L., \& Qin, X. (2014). Synthesis of $\mathrm{C}_{60} /$ Graphene composite as electrode in supercapacitors. Fullerenes, nanaotubes and carbonstructures, 23, 477-482.

Maggini, M., Guldi, D. M., Mondini, M., Scorrano, G., Poalucci, F., Ceroni, P., \& Roffia, S. (1998). Chem.-Eur. J., 4, 1992-2000.

Maggini, M., Scorrano, G., \& Prato, M. (1993). Addition of azomethine ylides to C60: synthesis, characterization, and functionalization of fullerene pyrrolidines. Journal of the American Chemical Society, 115(21), 97989799.

Makamura, E., \& Isobe, H., (2003). Functionlized fullerenes in water. The first 10 years of their chemistry, biology and nanoscience. Acc. Chem. Res., 36, 807-815.

Martin, N., Sánchez, L., Herranz, M. A., \& Guldi, D. M. (2000). Evidence for two separate one-electron transfer events in excited fulleropyrrolidine dyads containing tetrathiafulvalene (TTF). The Journal of Physical Chemistry A, 104(19), 4648-4657. 
Mauter, M. S., \& Elimelech, M. (2008). Environmental applications of carbon-based nanomaterials. Environmental Science \& Technology, 42(16), 5843-5859.

Michel, K. H. (1992). Molecular structure and orientational ordering in solid C60. The Journal of chemical physics, 97(7), 5155-5162.

Moussa, F., Pressac, M., \& Hadchouel, M. (1997). Fullerenes: recent advances in the chemistry and physics of fullerenes and related materials. The Electrochemical Society.

Nagashima, H., Nakaoka, A., Saito, Y., Kato, M., Kawanishi, T., \& Itoh, K. (1993). J. Chem. Soc. Chem. Commun., 4, 2153-2156.

Ohta, H., Saito, Y., Nagae, N., Pesek, J. J., Matyska, M. T., \& Jinno, K. (2000). Fullerenes separation with monomeric type C30 stationary phase in high-performance liquid chromatography. Journal of Chromatography A, 883(1-2), 55-66.

Osawa, E. (1970). Kagaku (Kyoto).

Park, S., Srivastava, D., \& Cho, K. (2001). External Chemical Reactivity of Fullerenes and Nanotubes. MRS Online Proceedings Library Archive, 675, 151-156.

Payne, M. C., Teter, M. P., Allan, D. C., Arias, T. A., \& Joannopoulos, J. D. (1992). Rev. Mod. Phys., 64, 1045.

Perfilove, S., Evodokimov, I., Pozdnjakov, A., \& Blank, V. (2015). Nanostructured Aluminum-matrix composite material reinforced with fullerene $\mathrm{C}_{60}$. Scientific proceedings XII international congress. Machines, technologies, materials, 1, 131.

Pirkle, W. H., \& Welch, C. J. (1991). An unusual effect of temperature on the chromatographic behavior of buckminsterfullerene. The Journal of Organic Chemistry, 56(25), 6973-6974.

Pyrzynska, K. (2007). Application of carbon sorbents for concentration and separation of metal ions. Analytical Sciences, 23, 631-637.

Qi, J., Tao, W., Wand, Y., \& Xue, G. (2018). Synthesis and application of carbon matrix composites. Materials physics and chemistry, 28-36.

Reichardt, C. (1990). Solvents and solvent effects in organic chemistry (2 ${ }^{\text {nd }}$ ed., chapt. 1). Weinhelm.

Riedel, I., \& Dyakonov, V. (2004). Influence of electronic transport properties of polymer fullerene blend on the performance of bulk heterojunction photovoltaic devices. Physics status solidi, 201, 1332-1341.

Rouff, R. S., Tse, D. S., Malhotra, R., \& Lorent, D. C. (1993). Solubility of $\mathrm{C}_{60}$ in a variety of solvents. J. Phys. Chem., 97, 3379-3383.

Sato, M., Idiom, T., Suzuki, K., \& Fujimoto, K. (1992). Proceedings on the symposium on primary and secondary lithium batteries. ESC proceedings, 91-23, 407.

Shanboh, P. P., \& Sundaram, N. G. (2015). Fullerenes revisited. Articles in resonance. https://doi.org/10.1007/s/2045-015-060-0

Sheka, E. F., Razbirin, B. S., \& Nelson, D. K. (2011). Continuous symmetry of C60 fullerene and its derivatives. The Journal of Physical Chemistry A, 115(15), 3480-3490.

Shen, Y., Reparaz, J. S., Wagner, M. R., Hoffmann, A., Thomsen, C., Lee, J. O., ... \& Seki, S. (2011). Assembly of carbon nanotubes and alkylated fullerenes: nanocarbon hybrid towards photovoltaic applications. Chemical Science, 2(11), 2243-2250.

Sisk, W. N., Kang, D. H., Raja, M. Y. A., \& Farahi, F. (1997). Photocurrent and optical limiting studies of C60 films and solutions. Intern. J. Optoelectronics, II, 325.

Smalley, R. E. (1991). Process for making fullerenes by laser evapouration of carbon. United States Patent, 5(300), $1-12$

Snow, S. D., Park, K., \& Kim, J. H. (2014). Photochemical and photophysical properties of sequentially functionalized fullerenes in aqueous phase. Environ. Sci. Techno. Lett., 1, 290-294.

Sokolov, V. I. (1999). Chemistry of fullerenes, novel allotropic modifications of carbon. Russian chemical bulletin, 48(7), 1197-1205.

Sokolov, V. I. (1999). Reviews: Chemistry of fullerenes, novel allotropic modifications of carbon. Russian Bulletin, $48,1197-1214$. 
Stankevich, I. V., Nikerov, M. V. E., \& Bochvar, D. A. E. (1984). The structural chemistry of crystalline carbon: geometry, stability, and electronic spectrum. Russian Chemical Reviews, 53(7), 640-655.

Subesma, R., Srodanov, G., Wudi, F., Castoro, J. A., Wilkins, C., Freidman, S. H., ... Kenyon, G. L. (1993). Synthesis of a fullerene derivative for the inhibition of HIV enzymes. J. Am. Chem. Soc., 115, 6510-6512.

Taylor, R., \& Walton, D. R. M. (1993). The chemistry of fullerenes. Nature, 363, 385-393.

Taylor, R., Langley, G. J., Holloay, J. H., Hope, E. G., Bridson, A. K., Kroto, H. W., \& Walton, D. R. M. (1995). Oxygenated species in the products of fluorination of [60] - and [70] fullerene by fluorine gas. J. Am. Chem. Soc. Perkin Transactions, 2, 188.

Thota, S., Wang, M., Jeon, S., Maragani, S., Hmblin, M. R., \& Chiang, L. Y. (2012). Synthesis and characterization of positively charged pentaionic [60] fullerene nano adducts for antimicrobial photodynamic inactivation. Molecules, 17, 5225-5243.

Thras, T. P., Gagle, D. W., Alford, J. M., Wright, K., Ehrhardt, G. J., Mirzadeh, S., \& Wilson, L. T. (1999). Towards fullerene based-radiopharmaceuticals: High yield neutron activation of Endohedral $165 \mathrm{HO}$ metallofullerenes $\mathrm{C}_{60}$ and $\mathrm{C}_{70}$ : The third form of carbon. Chem. Phys. Lett., 308, 329-336.

Toth, K. (2012). Endofullerene functionalization: from material science to biomedical applications. Thesis submitted to the Institute of physics and chemistry of materials, Strasburg. Department of organic materials. CNRS UMR, 7504, 12-15.

Troshin, K. R., Peregudov, A. S., Peregudova, S. S. M., Egginer, M., Lyubovvskaya, R. N., \& Saricifici, N. S. (2007). Pyrrolodinofullerene bearing chelating pyridyl groups and zinc phthalocyanine for organic solar cells. Chem. Mater., 19, 5363-5372.

Ulloa, E. (2013). Fullerenes and their Applications in Science and Technology. Introduction to Science and Technology.

Unwin, P. (2004). Fullerenes (an overview). Retrieved from http:www.ch.ic.ac.uk/local/projects/unwin

Vidyaev, D. G., Savostikov, D. V., Boretsky, E. A., \& Verkhorubov, D. L. (2016). Hydrogen sorption by carbon nanostructured materials. Jr. of Industrial pollution control, 32, 411-413.

Villegas, C., Delgado, J. L., Bouit, P.-A., Grimm, B., Seitz, W., Martin, N., \& Guldi, D. M. (2011). Powering reductive charge shift reactions-linking fullerenes of different electron acceptor strength to secure an energy gradient. Chem. Sc., 2, 1677-1681.

Wang, C. C., Guo, Z. X., Fu, S. K., Wu, W., \& Zhu, D. B. (2004). Polymer containing fullerene or carbon nanotube structures. Progr. Polym. Sc., 29, 1079-1141.

Wang, L. S., Alford, J. M., Chai, Y., Diener, M., Zhang, J., McClure, S. M., ... Smalley, R. E. (1993). The electronic structure of $\mathrm{Ca} @ \mathrm{C}_{60}$.Che. Phys.Lett., 207, 354-359.

Wang, Y., Wei, H., Lu, Y., Wei, S., Wujcik, E. K., \& Gou, Z. (2015). Multifunctional carbon nanostructures for advanced energy applications. Nanomaterials, 5, 755-777.

Weaver, J. H., Chai, Y., Kroll, G. H., Jin, C., Ohno, T. R., Haufler, R. E., ... \& Jain, A. (1992). XPS probes of carbon-caged metals. Chemical physics letters, 190(5), 460-464.

Wijnkoop, M., Meidine, M., Avent, A., Darwish, A., Kroto, H., \& Walton, D. M. (1997). Platinum (0)-[60] fullerene complexes with chelating diphosphine ligands. Syntheses and characterisation of [ $\mathrm{Pt}(\eta 2-\mathrm{C} 60)(\mathrm{L}-$ $\mathrm{L})][\mathrm{L}-\mathrm{L}=\mathrm{Ph} 2 \mathrm{P}(\mathrm{CH} 2) \mathrm{n} \mathrm{PPh} 2, \mathrm{n}=2$ or 3]. Journal of the Chemical Society, Dalton Transactions, (4), 675678.

Wood, J. M., Karh, B., Hake, S. H., Dejame, L-H., Cooks, R. G., \& Ben-Amotz, D. (1991). The chemistry of fullerenes. J. Am Che. Soc., 113, 5907.

Yadav, B. C., \& Kumar, R. (2008). Structure, properties and applications of fullerenes. International Journal of Nanotechnology and Applications, 2(1), 15-24.

Yamakoshi, Y., Umezawa, N., Ryu, A., Arakani, K., Miyata, N., Goda, Y., Masumizu, T., \& Magano, T. (2003). Active oxygen species generated from photo excited fullerene $\mathrm{C}_{60}$ as potential medicines. J. Am .Chem. Soc., 125, 12803-12809.

Yannoni, C. S., Johnson, R. D., Meijer, G., Bethune, D. S., \& Salem, J. R. (1991). Carbon-13 NMR study of the C60 cluster in the solid state: molecular motion and carbon chemical shift anisotropy. The Journal of Physical Chemistry, 95(1), 9-10. 
Yu, Z., Tetard, L., Zhai, L., \& Thomas, J. (2015). Supercapacitor electrode materials : Nanostructures from 0 to 3 dimensions. Energy Environ. Sci., 8, 702-730.

Zhang, Q. L., O'Brien, S. C., Heath, J. R., Liu, Y., Curl, R. F., Kroto, H. W., \& Smalley, R. E. (1986). Reactivity of large carbon clusters: spheroidal carbon shells and their possible relevance to the formation and morphology of soot. The Journal of Physical Chemistry, 90(4), 525-528.

Zhou, X., Liu, J., Jin, Z., Gu, Z., Wu, Y., \& Sun, Y. (2007). Solubilty of fullerene $\mathrm{C}_{60}$ and $\mathrm{C}_{70}$ in toluene, O-xylene and carbon disulfide at various temperatures. Fullerene science and technology, 5, 285-290.

\section{Copyrights}

Copyright for this article is retained by the author(s), with first publication rights granted to the journal.

This is an open-access article distributed under the terms and conditions of the Creative Commons Attribution license (http://creativecommons.org/licenses/by/4.0/). 